\title{
Revistas Permutadas
}

1. Alpha Omega / Roma

2. Analecta Cracoviensia

3. Anales de Teologia - de la Universidad Católica de la Santísima Concepción

4. Análise \& Síntese

5. Ângulo Cadernos do Centro Cultural Teresa D’Ávila

6. Antropologia / Bolívia

7. Cadernos da Estef - Fundação São Lourenço de Brindisi

8. Caesura / Ulbra

9. Ciências da Religião - Instituto Presbiteriano Mackenzie

10. Comunicaciones Komunikazioak - Espanha

11. Communio - Communio do Brasil

12. CRB - Convergência

13. Cuadernos - El Derecho de Acceso a La Vivienda

14. Custiones Teológicas y Filosóficas - Universidade Pontificia Bolivariana

15. Cultura e Fé - Instituto de Desnvolvimento Cultural

16. Didaskalia - Revista da Faculdade de Teologia / Lisboa

17. Direito e Pastoral - Instituo superior de Direito Canôonico

18. Ecclesia - Revista de Cultura Católica / Roma

19. Ecclesiastica Xaveriana

20. Encontros Teológicos - Instituto Teológico de Santa Catarina ITESC

21. Espaços - ITESP

22. Estúdios Sociales / Republica Dominicana

23. Estudos Teológicos - Escola Superior de Teologia / Rio Grande do Sul

24. Família et Vita

25. Filosofazer - Revista do Instituto Superior de Filosofia Berthier

26. Folia Theológica / Hungria

27. Franciscanum - Revista de Lãs Ciências Del Espiritu / Colombia

28. Horizonte - Revista de Estudos de Teologia e Ciências da Religião

29. Horizonte Teológico - Instituto Santo Tomás de Aquino - ISTA

30. Humanitas - Revista de Antropologia y Cultura Cristiana

31. Itaici - Revista de Espiritualidade Inaciana

32. Iter - Instituto de Teologia para Religiosos / Venezuela

33. Kairós - Revista Acadêmica da Prainha / Ceará 
34. Laos - Revista di Science Religiose e Humanistiche / Catania

35. Medellín - Teologia y Pastoral para América Latina

36. Mundo e Missão

37. Nigrizia - Revista Mensale Dei Missionari Colombiani

38. Notiziario Consejo Pontificio para los Laicos

39. Notizieuniversità Pontificia Salesiana / Roma

40. Numen - Universidade de Juiz de Fora

41. O Arauto - Boston

42. Páginas - Revista Acadêmica e Institucional de la UCPR Comombia

43. Path - Pontoficia Academia Theologica - Libreria Editrice Caticana / Roma

44. Perspectiva Teológica - Faculdade de Teologia da Companhia de Jesus

45. Phrónesis - Revista de Ética - PUC / Campinas - SIBI

46. Razão e Fé - Revista - Inter e Transdisciplinar de Teologia, Filosofia e Bioética

47. REB - Revista Eclesiastica Brasileira - Instituto Teológico Franciscano

48. Redes, Revista Capixaba de Filosofia e Teologia

49. Reflexão - Instituto de Filosofia - PUC / Campinas

50. Repensar - Revista de Filosofia e Teologia

51. Revista Caminhando com o Itepa

52. Revista de Cultura Teológica - Centro Universitário Assunção

53. Revista de Fragmentos de Cultura - IFTEG

54. Revista Iberoamericana de Teologia / México D.F.

55. Revista Isidorianum / Sevilla

56. Revista Latinoamericana de Teología

57. Revista Perspectivas - Institutos Superiores de Ensino do CENSA

58. Revista Proyeccion / Espanha

59. Revista Teologia - Faculdad de Teologia PUC / Argentina

60. Revista Teológica - Seminário TeológicoPresbiteriano Rev. Ashbel

61. Revista Trilhas - Revista Teológica Pastoral - FAMIPAR

62. Revue de L'Universite Catholique de Lyon

63. Rhema - Revista de Filosofia e Teologia - AACSSA

64. Rucao - Revue de L'Universite Catholique de L'Afrique de L'Quest

65. Seminarium / Itália

66. Seminary Studies - Andrews University Press

67. Spiritualità Monfortana / Roma

68. Spiritus - Equador

69. Stromata / Argentina

70. Studi Ecumenici - Venezuela

71. Studia Patavina - Rivista di Scienze Religiose 
72. Studium Filosofia y Teologia - Universidad del Norte Santo Tomas de Aquino

73. Tempo e Presença - Koinonia Presença Ecumênica e Serviço

74. Teocomunicação

75. Teologia - Revista della Facoltà Teológica dell'Italia Settentrionale

76. Teologia y Sociedad - Pontificia Universidad Javeriana / Cali

77. Teologia y Vida - Pontificia Universidad Católica / Chile

78. Theologia Xaveriana / Comombia

79. Theologiká - Revista de Estudos de Teologia e Comunicações

80. Theophilos - Revista de Teologia e Filosofia - Universidade Luterana do Brasil

81. The Princeton Seminary Bulletin / New Jersey

82. TQ - Teologia em Questão - Faculdade Dehoniana

83. Transversalités

84. Via Teológica - Faculdade Teológica Batista do Paraná

85. Vita e Pensiero / Milão

86. Voices From The Third World / India

87. Vox Scriptura - São Bento do Sul / Santa Catarina

88. Voz Amiga

89. Xilotil - Revista Nicarangüense de Teologia / Nicaragua

90. Yachay 


\section{Propagandas}

Livro: Deus justo e misericordioso na experiência de Abraão e do Servo Sofredor

Autor: Paulo F. Valério

Editora: PAULINAS

Formato: $(14,0$ x 21,0)

A comparação entre os textos do livro do Gênesis referentes à prece de Abraão em favor da cidade de Sodoma e o cântico do Servo de Javé, em Isaías, permitiu ao autor elaborar uma tese original, visto que esses dois textos, aparentemente sem relação, não só podem ser interpretados como respondendo à questão central da retribuição, mas também contêm elementos preciosos para a compreensão do que se vai tornar patente no gesto redentor de Jesus: o papel do justo na realização da salvação, salvaguardando a justiça e a misericórdia divinas.
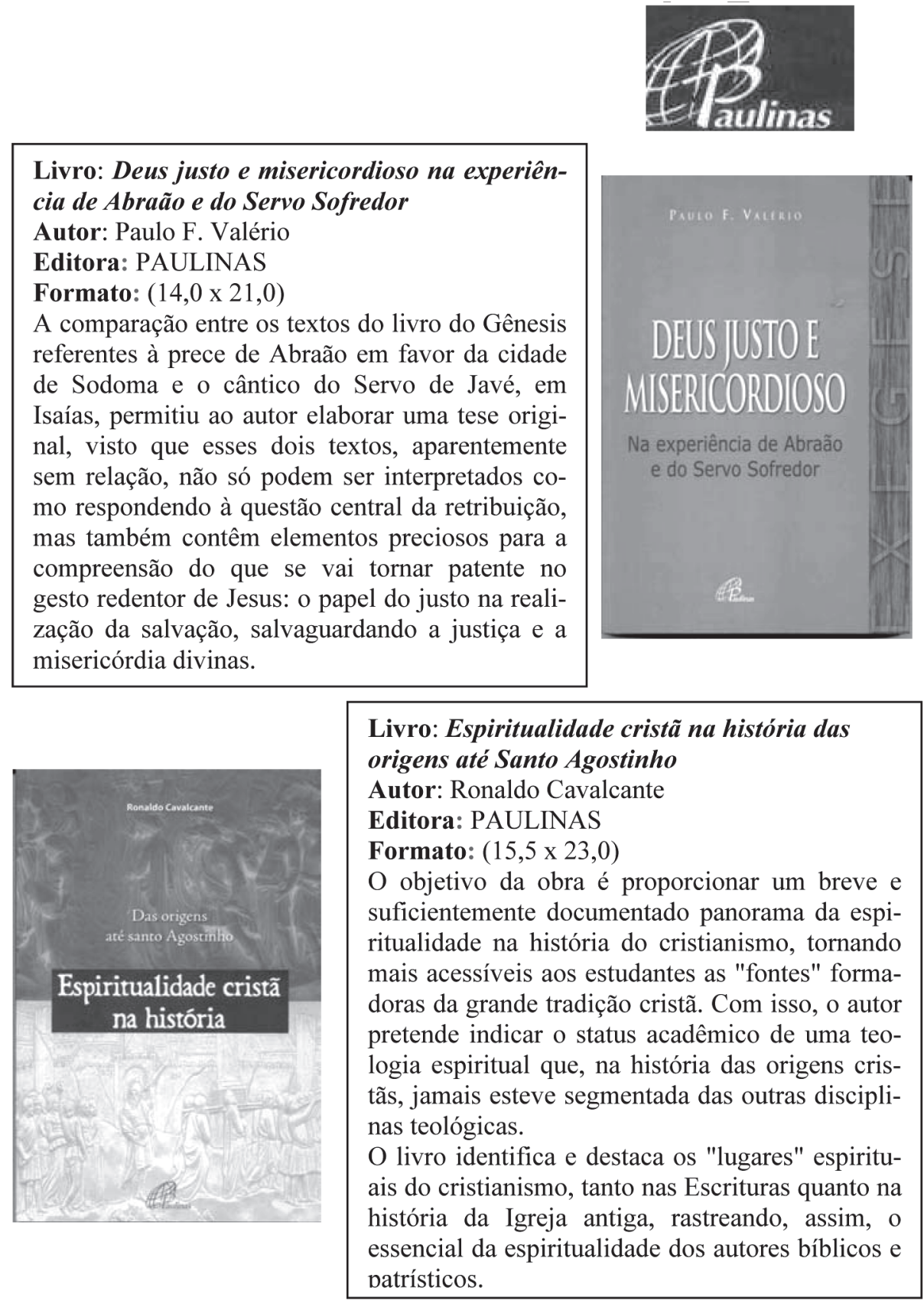


\section{Livro: Pluralismo religioso contemporâneo}

Autor: Roberlei Panasiewicz

Editora: PAULINAS

Formato: $(15,5$ x 23,0)

Na primeira parte, o leitor é introduzido à perspectiva hermenêutica de Geffré. A teologia desse pensador católico busca uma linguagem que fale humanamente de Deus; para isso, quer superar a teologia dogmática tradicional. Na segunda parte, o autor expõe as conseqüências dessa mentalidade para a teologia das religiões: repropõe o pluralismo religioso como desígnio de Deus, esclarece a dimensão cristológica que vê Jesus como universal concreto e recoloca em novos parâmetros a perspectiva eclesiológica da missão e a concepção de verdade. Trata-se de um sério esforço por apresentar uma teologia do pluralismo religioso.
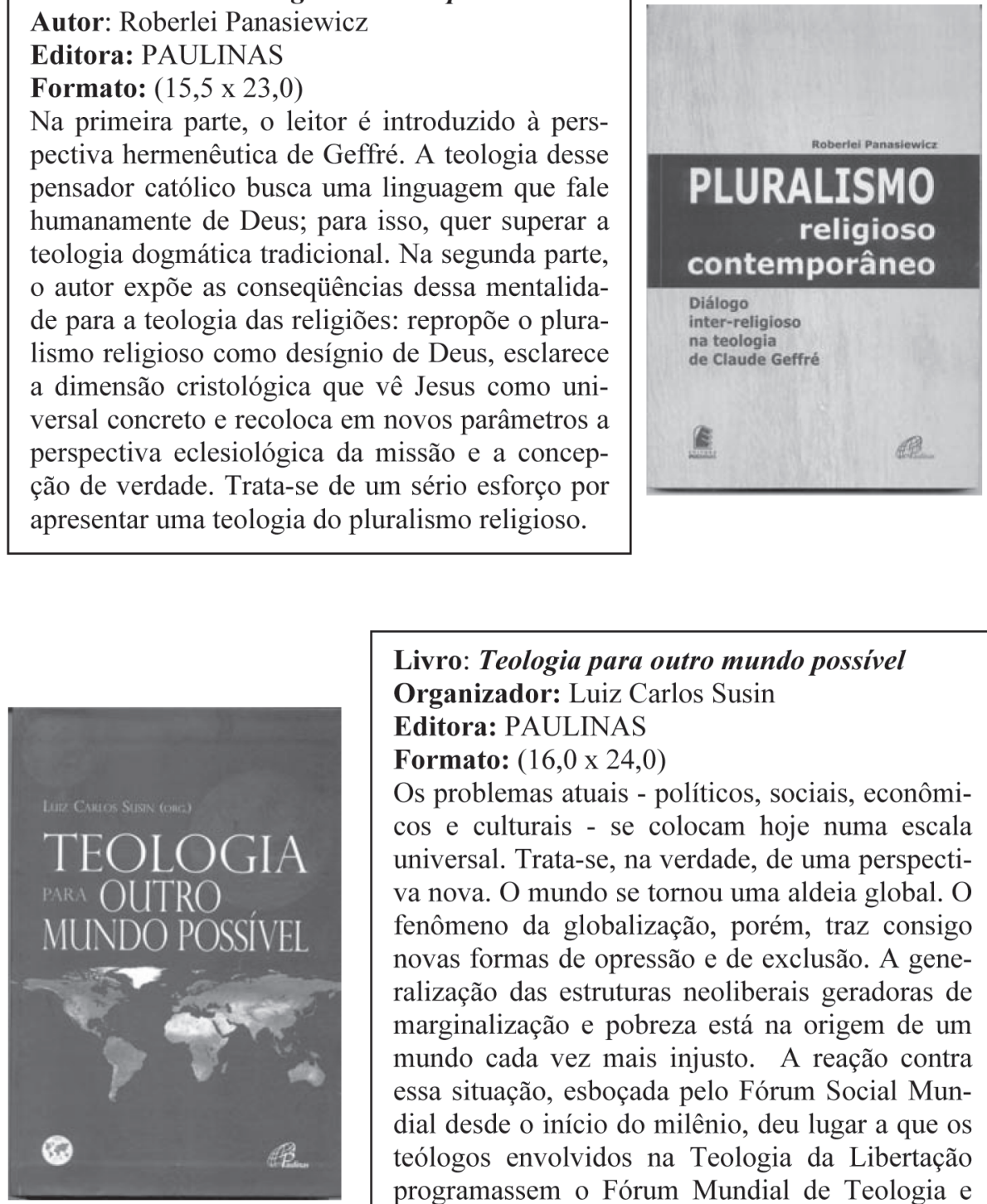

Livro: Teologia para outro mundo possível

Organizador: Luiz Carlos Susin

Editora: PAULINAS

Formato: $(16,0 \times 24,0)$

Os problemas atuais - políticos, sociais, econômicos e culturais - se colocam hoje numa escala universal. Trata-se, na verdade, de uma perspectiva nova. $\mathrm{O}$ mundo se tornou uma aldeia global. $\mathrm{O}$ fenômeno da globalização, porém, traz consigo novas formas de opressão e de exclusão. A generalização das estruturas neoliberais geradoras de marginalização e pobreza está na origem de um mundo cada vez mais injusto. A reação contra essa situação, esboçada pelo Fórum Social Mundial desde o início do milênio, deu lugar a que os teólogos envolvidos na Teologia da Libertação programassem o Fórum Mundial de Teologia e Libertação (FMTL), do qual resultou essa obra. 


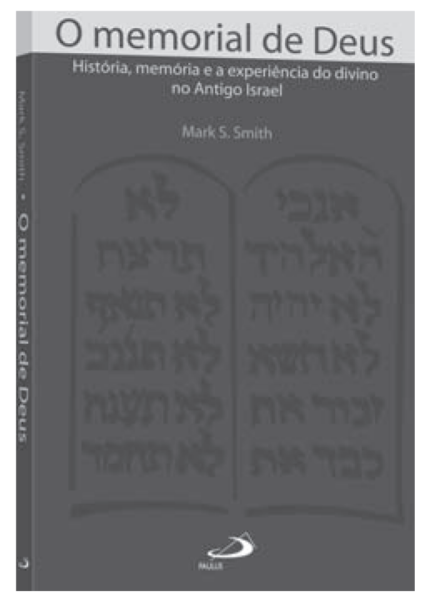

Livro: O memorial de Deus

Organizador: Mark S. Smith

Editora: PAULUS

Com o amplo conhecimento do autor sobre a literatura do Oriente Médio, a obra trata da complexa e fascinante história evolutiva da tradição e das crenças do Antigo Israel.

264 páginas $-\mathrm{R} \$ 37,00$

\section{Livro: Manual de sociologia da religião}

Organizador: Roberto Cipriani

Editora: PAULUS

Uma contribuição fundamental para a definição daquilo que possamos entender e definir como religião vem também da pesquisa de campo, que orienta, verifica e coloca em discussão os pontos de partida sobre a sociologia religiosa.

$$
360 \text { páginas }-\mathrm{R} \$ 31,00
$$

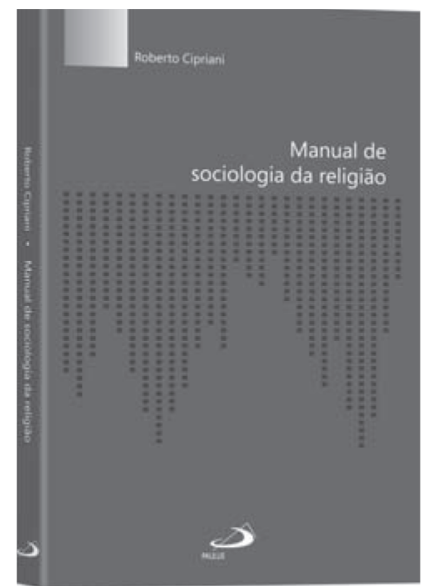




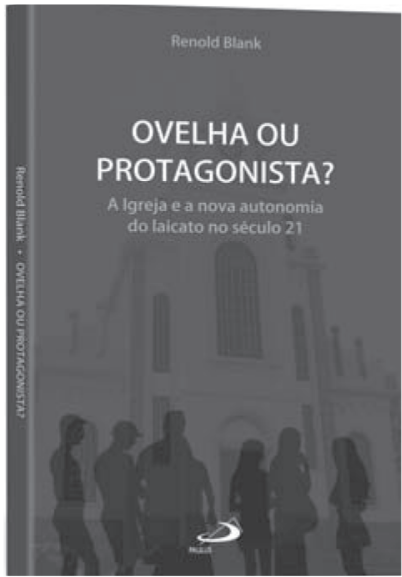

Livro: Ovelha ou protagonista

Organizador: Renold Blank

Editora: PAULUS

A nova obra do renomado Renold Blank toca em muitos pontos polêmicos do cotidiano da Igreja, principalmente no que diz respeito à hierarquia eclesial e sua relação com a atuação dos leigos.

168 páginas $-\mathrm{R} \$ 18,00$

Livro: Teologia do pluralismo religioso

Organizador: José Maria Vigil

Editora: PAULUS

Um instrumento didático pensado para apresentar aos leitores esta nova matéria com um tratamento pedagógico e pastoral adequado.

472 páginas - $\mathrm{R} \$ 60,00$

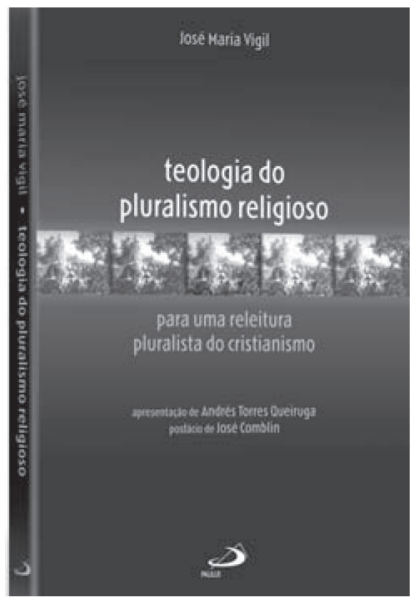

PAULUS Livraria Rio de Janeiro

Rua México, n. ${ }^{\circ} 111$ B - Castelo - Telefone: 2240-1303 